Article

\title{
Sustainability Evaluation of Cities in Northeastern China Using Dynamic TOPSIS-Entropy Methods
}

\author{
Weiwei Li ${ }^{1,2}$, Pingtao $\mathrm{Yi}^{1,2, *}$ and Danning Zhang ${ }^{3}$ \\ 1 School of Business Administration, Northeastern University, Shenyang 110167, China; \\ liww@mail.neu.edu.cn \\ 2 Northeastern Evaluation Center, Northeastern University, Shenyang 110167, China \\ 3 School of Economics, Liaoning University, Shenyang 110136, China; kathrinezdn@126.com \\ * Correspondence: ptyi@mail.neu.edu.cn or pintaoyi@gmail.com; Tel.: +86-24-8368-7616
}

Received: 10 November 2018; Accepted: 25 November 2018; Published: 2 December 2018

\begin{abstract}
The revitalization of Northeastern China has been an important topic in China in recent years. Sustainable development of cities plays a strong role in the revitalization process. In this paper, we evaluated the sustainability of the 34 prefecture-level and above cities in Northeastern China. The evaluation process was viewed as a dynamic evaluation problem. A dynamic technique for order preference by similarity to ideal solution (TOPSIS) and entropy method was developed by extending the entropy weight and TOPSIS to dynamic situation. It was found that the sustainability levels of the cities in Northeastern China were comparatively low. Only four sub-provincial cities' average performances were over 0.5 (accounting for 11.8\%). Except for Jixi, nearly all the cities had dim sustainability because of the lower positive or even negative growth rates. In addition to Shenyang, Dalian, Changchun, Harbin, and Daqing, the other cities performed worst in the economic sustainability with performance values below 0.3 . This implicates that the necessity and urgency of improving the economic sustainability levels of the cities in Northeastern China to realize the coordinated development of the three dimensions (economy, society and environment). In terms of the cities located in Liaoning province, they need to pay more attention to the economic sustainability, even though their economy basis (or levels) were comparatively better than that in Jilin and Heilongjiang provinces. For the cities in Jilin and Heilongjiang provinces, the decline of their environmental sustainability was serious. This case should arouse the attention of local authorities.
\end{abstract}

Keywords: sustainability development; sustainability evaluation; dynamic entropy method; dynamic TOPSIS; city sustainability

\section{Introduction}

Northeastern China was the cradle of new China's industry that had made a historic contribution to China's reform, opening up and modernization construction. Northeastern China once had 98\% of China's heavy industrial bases. However, the decline of Northeastern China was serious with the emerging of institutional and structural problems since 1990. In April 2016, the Communist Party of China (CPC) Central Committee and State Council jointly launched an important policy document entitled "Certain Opinions Regarding the Comprehensive Revival of Old Industrial Bases Including the Northeast" [1], which underlined the importance and urgency of improving city sustainability in Northeastern China [2].

A widely accepted definition of sustainability as given by [3] is "development that meets the needs of the present without compromising the ability of future generations to meet their own needs". Sustainability studies are popular for scholars and researchers in a wide range of fields [4-10]. An effective evaluation of sustainability is very important as it provides a useful framework for better decision-making on all 
undertakings, such as policies, plans and programs, as well as physical undertakings [11]. However, sustainability is not easily measurable since it is not directly indicated as a natural or direct consequence of the reading of the indicators [12]. A widely accepted approach is about developing a framework or model by involving a number of sustainability criteria. The selection of sustainability criteria is a key factor that may have a great influence on the sustainable performance. In applications, the three-pole or three-pillar model [13-15] was widely used for selecting sustainability criteria by considering the dimensions of economy, society, and environment, simultaneously. For more references about the selection of sustainability criteria with other considerations, please refer to [16-18].

As the matrix of sustainability criteria is usually large and complicated, the evaluation process is viewed as a multi-criteria decision-making (MCDM) problem. The basic MCDM process usually involves the procedures of colleting criteria data, inputting missing data, normalizing actual data, weighting criteria and aggregating normalized data and the associated weights [19]. Even though all the steps are important for the quality of sustainability evaluation, the weight and aggregation steps seem to have the greatest impact [20]. Many weighting methods were used for calculating criteria weights [21-27]. The entropy [28] is a widely used method. The basic logic of the method is that when the differences between a criterion's values across particular alternatives are larger, the weight is higher. Zinatizadeh et al. applied the Shannon's entropy to obtain the criteria weights used for constructing the composite indicator, which was developed to measure the urban sustainability in Kermanshah [29]. Munier developed a set of sustainability indicators as a baseline to measure the state of a city, where the entropy method was used for weighting the selected indicators [30]. Lin et al. used the information entropy to analyze the sustainable ability of the urban ecosystem in Guangzhou and suggested some measures to promote its sustainability [31].

The technique for order preference by similarity to ideal solution (TOPSIS) [32] is a popular method used in MCDM for aggregating multiple criteria and ranking various alternatives [33-35]. TOPSIS simultaneously considers the distances to both the positive and the negative ideal solutions. And a preference order is ranked according to their relative closeness and a combination of these two distance measures [36]. Many studies used TOPSIS as a basic tool for sustainability measurement at different scales, such as international regions, countries, states and cities. Alptekin used the TOPSIS to evaluate the 28 European Union countries and Turkey, and found that Sweden is the most sustainable country among EU countries [37]. Sen et al. evaluated the sustainability of different states in India based on the United Nations CSD indicators framework and TOPSIS and other methods, and found that Maharashtra performed best [38]. Balcerzak et al. used TOPSIS to examine the progress achieved by European countries in the field of implementing the concept of sustainable development and found that the new member states of European Union made a significant progress [39]. Dias et al. applied the TOPSIS to analyze the sustainability of countries at worldwide and demonstrated that the three most sustainable countries were Switzerland, Sweden and Norway [40]. Lu et al. investigated the resource-based cities in Northeastern China by adopting the TOPSIS method [2]. Ding et al. used the TOPSIS-entropy method to quantitatively evaluate the sustainable development of 287 cities at prefecture level and above in China. It concluded that the overall level of urban sustainability in China was not high, and obvious differences existed in urban sustainable development [41]. Liang et al. developed a Grey TOPSIS method for measuring the sustainable capacity of 13 cities in Jiangsu province, China, and found Suzhou had the highest sustainable capacity [42]. Guo et al. studied the urban sustainable competitiveness of 141 cities from 28 Chinese urban clusters in 2009 by using TOPSIS [43].

The state council approved the 12th five-year plan for the revitalization of Northeastern China in 2012. It pointed out to establish a long-term mechanism for promoting sustainable development of cities in Northeastern China. Therefore, taking the year of 2012 as the base period, this paper evaluated the dynamic sustainability of the 34 prefecture-level and above cities in Northeastern China over the following five consecutive years. The dynamic evaluation results provided more references for cities' sustainable development, including development status, trend, impetus and others. Notably, 
five years (2012 to 2016) were considered since the data of the criteria built in this paper were only released to the year 2016 at present. Additionally, in addition to the 34 prefecture-level and above cities, Northeastern China also includes an autonomous prefecture (Yanbian Korean Autonomous Prefecture) and a prefectural administrative region (Greater Khingan Range). As the lack data with respect to the two regions, we only investigated the sustainability of the 34 prefecture-level and above cities. The cities were introduced in the following section in more detail.

Many studies were developed to investigate sustainability of objects at different scales in various years $[2,29,44,45]$. For example, Shen et al. presented an evaluation on the dynamic sustainability performance during urbanization process in the countries of Brazil, Russia, India, China, and South Africa from the year 1990 to 2011. It was found that during the surveyed period the Brazil, Russia, and India had been engaging a sustainable urbanization practice. Whilst the urbanization processes in China and South Africa were unsustainable [46]. Lin et al. assessed the dynamic sustainability of Shanghai from the aspect of tourism ecological footprint. The evaluation results indicated there had been tourism ecological deficit in Shanghai from 2008 to 2013, showing that the pressure of tourism ecosystem was high and the Shanghai tourism was in unsustainable development state [47]. However, for most studies, they did not consider the overall performances of an object on a certain criterion across different years. For example, the criteria weights were usually calculated within a single year and were different in various years. This may reduce the comparability of the evaluation results in different years. To this problem, we extended the mean range normalization, entropy weighting method and TOPSIS to dynamic situation and developed a dynamic TOPSIS-entropy method. TOPSIS method was chosen as both the best and the worst points of view are considered simultaneously [2,36]. The entropy method was selected for its objective processing process without considering decision maker's subjective judgment. Unreasonable or inconsistent judgments of the decision makers may reduce the credibility of evaluation results. The cities sustainability in Northeastern China was measured based on the three-pillar model by selecting sustainability criteria from economic, social, and environmental dimensions.

The rest of the paper is organized as follows. Section 2 provides a brief introduction of the study cases. Section 3 proposes the dynamic TOPSIS-entropy methods used for city sustainability evaluation. The evaluation results are shown in Section 4. Conclusions, suggestions, and future works are outlined in Section 5.

\section{Study Cases}

Northeastern China is an important industrial base of China. It covers 788,000 km, accounting for $8.2 \%$ of China's total land area. Three provinces, Liaoning, Jilin, and Heilongjiang, locate in Northeastern China. Liaoning province lies between longitudes $118^{\circ} 53^{\prime} \mathrm{E}$ and $125^{\circ} 53^{\prime} \mathrm{N}$, and between latitudes $38^{\circ} 43^{\prime} \mathrm{N}$ and $43^{\circ} 26^{\prime}$ E. There are 14 cities located in Liaoning province, with two sub-provincial cities: Shenyang and Dalian. Jilin province lies between longitudes $121^{\circ} 38^{\prime} \mathrm{E}$ and $131^{\circ} 19^{\prime} \mathrm{N}$, and between latitudes $40^{\circ} 52^{\prime} \mathrm{N}$ and $46^{\circ} 18^{\prime} \mathrm{E}$. It has jurisdiction over 7 prefecture-level cities and one sub-provincial city, Changchun. Heilongjiang province lies between longitudes $121^{\circ} 11^{\prime} \mathrm{E}$ and $135^{\circ} 05^{\prime} \mathrm{N}$, and between latitudes $43^{\circ} 26^{\prime} \mathrm{N}$ and $53^{\circ} 33^{\prime}$ E. 12 cities locate in Heilongjiang province. Harbin is the sub-provincial city of Heilongjiang. The locations of the total 34 prefecture-level and above cities in Northeastern China are shown in Figure 1.

Northeastern China had made important contributions to China's independent and complete industrial system and national economic system. However, with the deepening of reform and opening up, the institutional and structural contradictions of Northeastern China have become increasingly prominent since 1990. This resulted in many problems hindering the sustainable development of Northeastern China, including severe economic recession, greater social security and livelihood pressures, imperfect private economy, lackluster state-owned enterprises, etc. For example, in the year 2014 to 2015, the economic growth rate of Northeastern China was at the bottom and was 1 to 2 percentage points behind the national average [48]. At present, the revitalization of Northeastern 
China is a core issue and policy-priority for Chinese government. The primary purpose of the paper is to investigate the dynamic sustainability of the cities in Northeastern China to provide more technology or policy reference for the sustainable development of Northeastern China. To achieve this, the following framework is proposed, as shown in Figure 2, where the key methods are described in the following subsections.

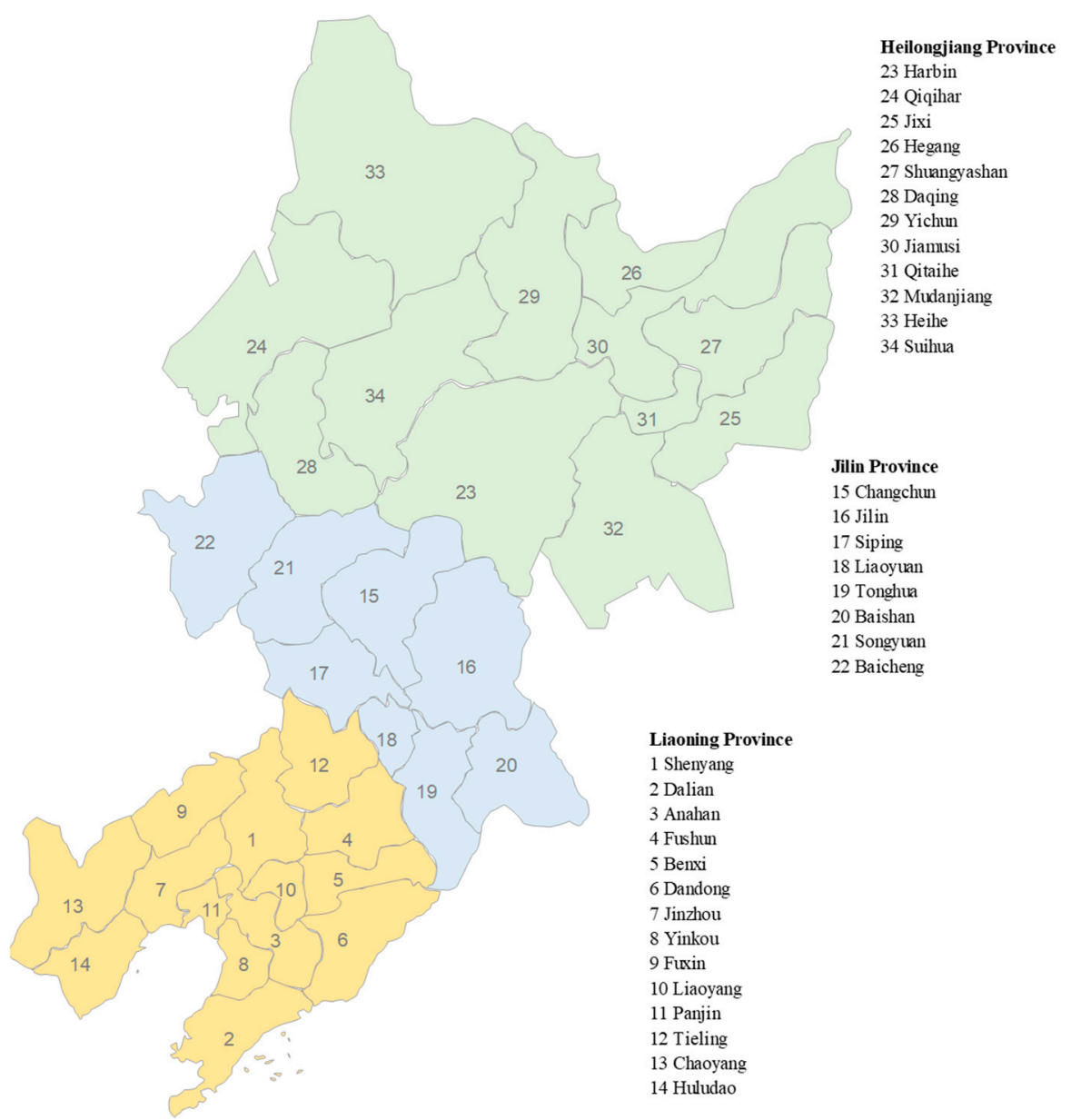

Figure 1. Locations of the studied cities in Northeastern China.

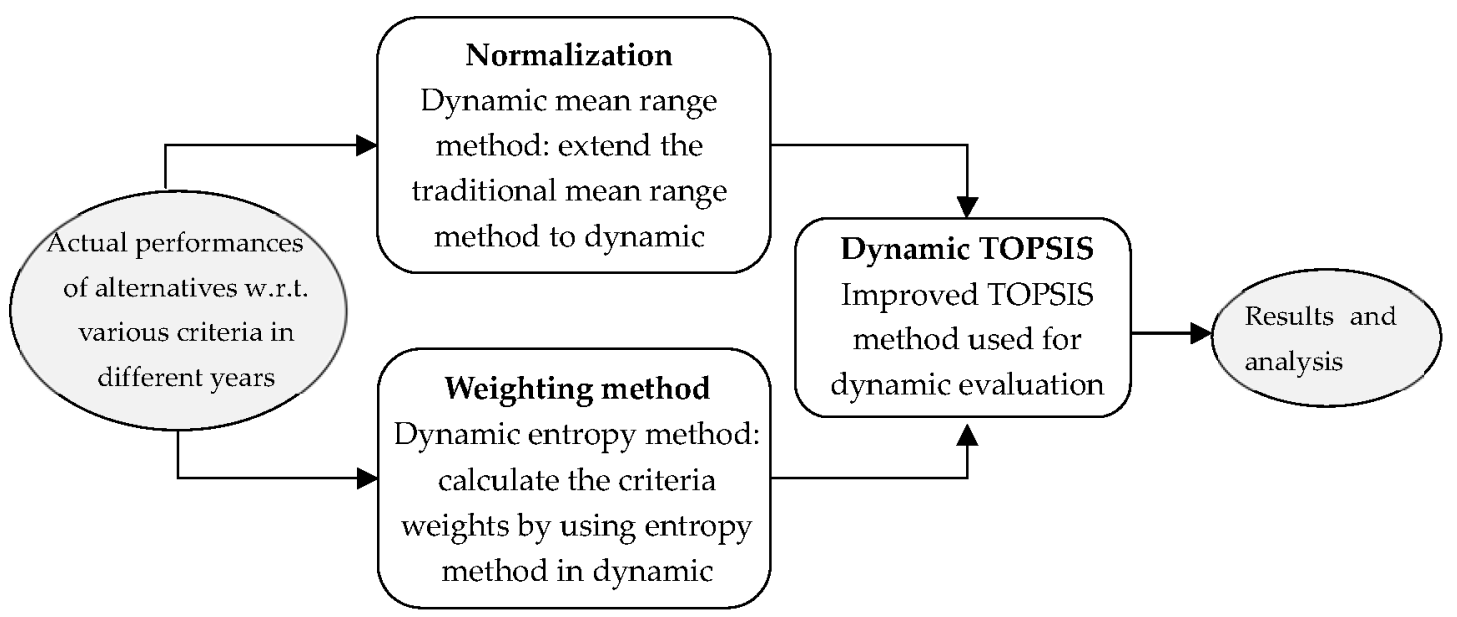

Figure 2. The framework of the research. 


\section{Methods}

\subsection{Criteria for Sustainability Evaluation}

The evaluation of city sustainability is not easy since it cannot be directly measured. Generally, a widely accepted approach is to select a set of criteria used for reflecting different dimensions of the sustainable development, such as the economic, social, and environmental dimensions. In terms of city sustainability, there is no a set of common recognized criteria for measuring sustainable development. In this paper, we developed a set of 21 criteria based on the three-pillar model and the combined consideration of the main literature reviews regarding sustainability investigation of Chinese cities $[2,25,41,48]$ and the accessibility of the criteria data. The 21 criteria were grouped into economic, social, and environmental dimensions, as shown in Table 1.

Table 1. Criteria for sustainability evaluation of cities in Northeastern China.

\begin{tabular}{|c|c|c|c|c|c|}
\hline Dimension & Criteria [Code] & Unit & Property & References & Weight \\
\hline \multirow{7}{*}{ Economy } & GDP per capita $\left[\mathrm{X}_{1}\right]$ & Yuan & Benefit & {$[2,25,41,49,50]$} & 0.0345 \\
\hline & $\begin{array}{l}\text { Per industrial enterprise gross } \\
\text { industrial output value }\left[\mathrm{X}_{2}\right]\end{array}$ & 10,000 Yuan & Benefit & {$[49]^{*}$} & 0.0376 \\
\hline & $\begin{array}{l}\text { Per capita retail sales of consumer } \\
\text { goods }\left[X_{3}\right]\end{array}$ & 10,000 Yuan & Benefit & {$[41,44,45,49]$} & 0.0380 \\
\hline & $\begin{array}{l}\text { Per capita investment in fixed assets } \\
{\left[\mathrm{X}_{4}\right]}\end{array}$ & Yuan & Benefit & {$[25,49]$} & 0.0557 \\
\hline & $\begin{array}{l}\text { Proportion of GDP generated by the } \\
\text { service industry }\left[\mathrm{X}_{5}\right]\end{array}$ & $\%$ & Benefit & {$[2,25,41,44-46,49,50]$} & 0.0056 \\
\hline & $\begin{array}{l}\text { Per industrial enterprise amount of } \\
\text { foreign capita utilized }\left[\mathrm{X}_{6}\right]\end{array}$ & 10,000 USD & Benefit & {$[49]^{*}$} & 0.1208 \\
\hline & Household saving deposits $\left[X_{7}\right]$ & 10,000 Yuan & Benefit & {$[49]^{*}$} & 0.1076 \\
\hline \multirow{7}{*}{ Society } & Population density $\left[\mathrm{X}_{8}\right]$ & Person $/ \mathrm{Km}^{2}$ & Benefit & {$[25,41,46,49]$} & 0.0577 \\
\hline & $\begin{array}{l}\text { Registered urban unemployment rate } \\
{\left[\mathrm{X}_{9}\right]}\end{array}$ & $\%$ & Cost & {$[2,25,41,44-46,51]$} & 0.0201 \\
\hline & $\begin{array}{l}\text { Average wage of employed staff and } \\
\text { workers }\left[\mathrm{X}_{10}\right]\end{array}$ & Yuan & Benefit & {$[45,49]$} & 0.0067 \\
\hline & $\begin{array}{l}\text { Ratio of education expenditure and the } \\
\text { public finance expenditure }\left[\mathrm{X}_{11}\right]\end{array}$ & $\%$ & Benefit & {$[2,41,45,46]$} & 0.0085 \\
\hline & $\begin{array}{l}\text { Ratio of science and technology } \\
\text { expenditure and the public finance } \\
\text { expenditure }\left[\mathrm{X}_{12}\right]\end{array}$ & $\%$ & Benefit & {$[2,41,45,46]$} & 0.0875 \\
\hline & $\begin{array}{l}\text { Beds of medical institutions per } 10,000 \\
\text { population }\left[\mathrm{X}_{13}\right]\end{array}$ & Unit & Benefit & {$[2,25,41,45,49,51]$} & 0.0085 \\
\hline & Per capita area of paved roads $\left[\mathrm{X}_{14}\right]$ & $\mathrm{m}^{2}$ & Benefit & {$[25,41,48]$} & 0.0349 \\
\hline \multirow{7}{*}{ Environment } & $\begin{array}{l}\text { Ratio green coverage of built up areas } \\
{\left[\mathrm{X}_{15}\right]}\end{array}$ & $\%$ & Benefit & {$[2,25,41,45,49,51]$} & 0.0080 \\
\hline & Per capita green area $\left[\mathrm{X}_{16}\right]$ & $\mathrm{m}^{2}$ & Benefit & {$[2,49]$} & 0.0999 \\
\hline & $\begin{array}{l}\text { Per industrial enterprise waste water } \\
\text { discharged }\left[\mathrm{X}_{17}\right]\end{array}$ & 10,000 Ton & Cost & {$[2,25,41,45,49,51]$} & 0.0812 \\
\hline & $\begin{array}{l}\text { Per industrial enterprise } \mathrm{SO}_{2} \text { emissions } \\
{\left[\mathrm{X}_{18}\right]}\end{array}$ & Ton & Cost & {$[2,41,49-51]$} & 0.0604 \\
\hline & $\begin{array}{l}\text { Ratio of industrial solid wastes } \\
\text { comprehensively utilized }\left[\mathrm{X}_{19}\right]\end{array}$ & $\%$ & Benefit & {$[25,41,44-47,49]$} & 0.0168 \\
\hline & Ratio of waste water treated $\left[\mathrm{X}_{20}\right]$ & $\%$ & Benefit & {$[41,44-47,49]$} & 0.0060 \\
\hline & $\begin{array}{l}\text { Per industrial enterprise smoke and } \\
\text { dust emissions }\left[\mathrm{X}_{21}\right]\end{array}$ & Ton & Cost & {$[2,25,49]$} & 0.1042 \\
\hline
\end{tabular}

Note: * represents a similar criterion.

Economic sustainability serves as the guarantee of city sustainability. We considered the quantity of economic growth as well as the quality of economy. As one of the important criteria of economic sustainability, $X_{1}$ directly reflects the economic level of an individual city; $X_{2}$ indicates the industrial development; $X_{3}$ represents the people's consumption level and purchasing power of social commodities [41]; $\mathrm{X}_{4}$ was chosen for measuring the capability of enlarging reproduction; $\mathrm{X}_{5}$ shows the 
development of the service industry and industrial structure; $X_{6}$ reflects the degree of the economy openness of a city; $X_{7}$ is an important criterion used for measuring residents' richness.

In terms of social sustainability, we mainly focused on the population of a city, the quality of human life, the development of education and technology, etc. Social sustainability serves as the ultimate goal of city sustainability. Specially, $\mathrm{X}_{8}$ reflects the distribution and density of population of a city; $X_{9}$ indicates the state of unemployment and social stability; $X_{10}$ represents the vital interests of workers at present and even after retirement; $X_{11}$ and $X_{12}$ show the development of education and technology, respectively; $X_{13}$ indicates the current situation of medical treatments; and $X_{14}$ shows the degree of traffic, which ensures communication and transportation of social and economic activities [41].

Environmental sustainability is the basis of city sustainability, which primarily focused on environmental protection, pollution controls and treatment in the paper. In Table $1, X_{15}$ and $X_{16}$ represent the situation of green cover within a city region; $X_{17}, X_{18}$, and $X_{21}$ revel the discharge levels of waste water and two types of air pollutions caused by industrial development, respectively; $X_{19}$ reflects the status of solid wastes disposal, and $X_{20}$ shows the disposal of waste water.

\subsection{Dynamic Entropy Weighting Method}

Without loss of generality, let $x_{i j}\left(t_{h}\right)$ represent the actual performance value of alternative (city) $o_{i}$ with respect to criterion $c_{j}$ in the year $t_{h}$, where $i=1,2, \cdots, n, j=1,2, \cdots, m, h=1,2, \cdots, L$.

The entropy weighting method was selected for its simplification, easy understanding, and objective data information. The basic process of the method is to determine criteria weights through entropy sum on each criterion for all alternatives [52]. Larger entropy sum indicates smaller changes of the associated criterion values. This means the criterion will be given small weight as it has a small contribution to the final evaluation result, and vice versa. More specifically, the entropy of the criterion $c_{j}$ was calculated by:

$$
E_{j}=-k \sum_{i=1}^{n} p_{i j} \ln p_{i j}, j=1,2, \cdots, m
$$

where $k=1 / \ln n$ is a constant that guarantees $E_{j} \in[0,1] ; p_{i j}=x_{i j} / \sum_{i=1}^{n} x_{i j}$ is the normalization value of the original criterion values $x_{i j}$, and if $p_{i j}=0$, let $p_{i j} \ln p_{i j}=0$.

As the entropy weight was used for dynamic evaluation of cities sustainability in the paper, the entropy sum needed to reflect the change of the criterion values across different years. To achieve this, we extended the entropy weighting method to dynamic evaluation problems, such as:

$$
E_{j}=-k \sum_{h=1}^{L} \sum_{i=1}^{n} p_{i j}\left(t_{h}\right) \ln p_{i j}\left(t_{h}\right)
$$

where $k=1 / \ln (L \times n), p_{i j}\left(t_{h}\right)=x_{i j}\left(t_{h}\right) / \sum_{h=1}^{L} \sum_{i=1}^{n} x_{i j}\left(t_{h}\right)$.

The entropy weight of criterion $c_{j}$ was calculated by:

$$
w_{j}=\frac{1-E_{j}}{\sum_{j=1}^{m}\left(1-E_{j}\right)}
$$

where $w_{j} \in[0,1]$ and $\sum_{j=1}^{m} w_{j}=1$.

Using the Equations (2) and (3), we calculated the criteria weights as shown in the last column in Table 2. 
Table 2. Sustainable performances of the 34 prefecture-level and above cities in Northeastern China.

\begin{tabular}{|c|c|c|c|c|c|c|c|c|c|}
\hline \multirow{2}{*}{ Province } & \multirow{2}{*}{ City } & \multicolumn{5}{|c|}{ Performance Value } & \multirow{2}{*}{ Mean $^{a}$} & \multirow{2}{*}{ Ranking $^{b}$} & \multirow{2}{*}{ Growth Rate ${ }^{c}$} \\
\hline & & 2012 & 2013 & 2014 & 2015 & 2016 & & & \\
\hline \multirow{14}{*}{ Liaoning } & Shenyang & 0.596 & 0.611 & 0.582 & 0.576 & 0.566 & 0.586 & 2 & $-1.27 \%$ \\
\hline & Dalian & 0.671 & 0.694 & 0.696 & 0.553 & 0.566 & 0.636 & 1 & $-3.91 \%$ \\
\hline & Anshan & 0.424 & 0.429 & 0.443 & 0.405 & 0.400 & 0.420 & 9 & $-1.41 \%$ \\
\hline & Fushun & 0.408 & 0.423 & 0.414 & 0.382 & 0.338 & 0.393 & 19 & $-4.25 \%$ \\
\hline & Benxi & 0.390 & 0.413 & 0.387 & 0.415 & 0.354 & 0.392 & 20 & $-2.35 \%$ \\
\hline & Dandong & 0.415 & 0.421 & 0.410 & 0.392 & 0.398 & 0.407 & 12 & $-1.04 \%$ \\
\hline & Jinzhou & 0.421 & 0.438 & 0.439 & 0.396 & 0.398 & 0.418 & 10 & $-1.34 \%$ \\
\hline & Yingkou & 0.452 & 0.457 & 0.435 & 0.410 & 0.383 & 0.427 & 7 & $-3.83 \%$ \\
\hline & Fuxin & 0.366 & 0.372 & 0.363 & 0.341 & 0.368 & 0.362 & 28 & $0.17 \%$ \\
\hline & Liaoyang & 0.395 & 0.417 & 0.415 & 0.382 & 0.371 & 0.396 & 18 & $-1.54 \%$ \\
\hline & Panjin & 0.466 & 0.467 & 0.451 & 0.423 & 0.416 & 0.445 & 6 & $-2.69 \%$ \\
\hline & Tieling & 0.424 & 0.425 & 0.422 & 0.366 & 0.380 & 0.403 & 13 & $-2.60 \%$ \\
\hline & Chaoyang & 0.385 & 0.391 & 0.380 & 0.352 & 0.337 & 0.369 & 27 & $-3.09 \%$ \\
\hline & Huludao & 0.391 & 0.407 & 0.396 & 0.354 & 0.329 & 0.375 & 26 & $-4.00 \%$ \\
\hline \multirow{8}{*}{ Jilin } & Changchun & 0.534 & 0.564 & 0.585 & 0.590 & 0.616 & 0.578 & 3 & $3.86 \%$ \\
\hline & Jilin & 0.407 & 0.418 & 0.426 & 0.419 & 0.435 & 0.421 & 8 & $1.73 \%$ \\
\hline & Siping & 0.372 & 0.377 & 0.373 & 0.393 & 0.410 & 0.385 & 22 & $2.54 \%$ \\
\hline & Liaoyuan & 0.404 & 0.408 & 0.398 & 0.409 & 0.432 & 0.410 & 11 & $1.73 \%$ \\
\hline & Tonghua & 0.375 & 0.414 & 0.382 & 0.393 & 0.449 & 0.403 & 14 & $4.91 \%$ \\
\hline & Baishan & 0.388 & 0.399 & 0.399 & 0.402 & 0.418 & 0.401 & 15 & $1.90 \%$ \\
\hline & Songyuan & 0.385 & 0.386 & 0.393 & 0.399 & 0.422 & 0.397 & 16 & $2.39 \%$ \\
\hline & Baicheng & 0.374 & 0.379 & 0.382 & 0.389 & 0.406 & 0.386 & 21 & $2.13 \%$ \\
\hline \multirow{12}{*}{ Heilongjiang } & Haibin & 0.489 & 0.499 & 0.498 & 0.523 & 0.541 & 0.510 & 4 & $2.64 \%$ \\
\hline & Qiqihar & 0.380 & 0.392 & 0.400 & 0.354 & 0.392 & 0.384 & 24 & $0.77 \%$ \\
\hline & Jixi & 0.236 & 0.220 & 0.254 & 0.346 & 0.399 & 0.291 & 33 & $17.23 \%$ \\
\hline & Hegang & 0.309 & 0.337 & 0.298 & 0.290 & 0.311 & 0.309 & 31 & $0.19 \%$ \\
\hline & Shuangyashan & 0.307 & 0.285 & 0.264 & 0.220 & 0.275 & 0.270 & 34 & $-2.61 \%$ \\
\hline & Daqing & 0.448 & 0.476 & 0.472 & 0.474 & 0.490 & 0.472 & 5 & $2.30 \%$ \\
\hline & Yichun & 0.326 & 0.341 & 0.311 & 0.310 & 0.351 & 0.328 & 30 & $1.92 \%$ \\
\hline & Jiamusi & 0.370 & 0.373 & 0.380 & 0.403 & 0.396 & 0.384 & 23 & $1.76 \%$ \\
\hline & Qitaihe & 0.288 & 0.293 & 0.288 & 0.297 & 0.313 & 0.296 & 32 & $2.16 \%$ \\
\hline & Mudanjiang & 0.379 & 0.390 & 0.404 & 0.414 & 0.396 & 0.397 & 17 & $1.13 \%$ \\
\hline & Heihe & 0.335 & 0.343 & 0.322 & 0.365 & 0.369 & 0.347 & 29 & $2.58 \%$ \\
\hline & Suihua & 0.381 & 0.362 & 0.358 & 0.389 & 0.405 & 0.379 & 25 & $1.56 \%$ \\
\hline
\end{tabular}

Notes: a Mean represents the average level of the cities' sustainability, which was calculated by the average of the performance values in the year 2012 to 2016 ; $^{\mathrm{b}}$ Ranking was obtained by the mean values associated; ${ }^{\mathrm{c}}$ Growth rate represents the average annual growth rate of the sustainable performance value, which was calculated by $\left(C_{i}(2016)\right.$ $\left.-C_{i}(2012)\right) / C_{i}(2012) / 4 \times 100 \%$.

\subsection{Dynamic TOPSIS Model}

TOPSIS was firstly proposed by Hwang and Yoon in 1981 [32]. This method objectively and comprehensively reflects the sustainability level by calculating the closeness degree between an evaluation value and its ideal solutions [41]. We concluded the basic steps of the TOPSIS used for dynamic evaluation problems as follows.

Step 1. Scale the actual criteria values into a uniform range:

$$
\left\{\begin{array}{l}
y_{i j}\left(t_{h}\right)=\frac{x_{i j}\left(t_{h}\right)-x_{\min (j)}}{x_{\max (j)}-x_{\min (j)}}, \text { if } c_{j} \text { is a benefit criterion } \\
y_{i j}\left(t_{h}\right)=\frac{x_{\max (j)}-x_{i j}\left(t_{h}\right)}{x_{\max (j)}-x_{\min (j)}}, \text { if } c_{j} \text { is a cost criterion }
\end{array}\right.
$$

where $x_{\max (j)}$ and $x_{\min (j)}$ represent the maximum and minimum value of criterion $c_{j}$ across all the evaluation years, respectively, such that $x_{\max (j)}=\max \left\{x_{1 j}\left(t_{1}\right), \cdots, x_{n j}\left(t_{1}\right), \cdots, x_{1 j}\left(t_{L}\right), \cdots, x_{n j}\left(t_{L}\right)\right\}$, $x_{\min (j)}=\min \left\{x_{1 j}\left(t_{1}\right), \cdots, x_{n j}\left(t_{1}\right), \cdots, x_{1 j}\left(t_{L}\right), \cdots, x_{n j}\left(t_{L}\right)\right\}$. We see that $y_{i j}\left(t_{h}\right) \in[0,1]$. 
Step 2. Weight the normalized criteria values using the associated dynamic entropy weights calculated by Equations (2) and (3):

$$
u_{i j}\left(t_{h}\right)=w_{j} y_{i j}\left(t_{h}\right), i=1,2, \cdots, n, j=1,2, \cdots, m, h=1,2, \cdots, L
$$

Step 3. Determine the best solution $u_{j}^{+}$and the worst solution $u_{j}^{-}$on criterion $c_{j}$ :

$$
\begin{aligned}
& u_{j}^{+}=\max \left\{u_{i j}\left(t_{h}\right), i=1,2 \cdots, n ; h=1,2 \cdots, L\right\} \\
& u_{j}^{-}=\min \left\{u_{i j}\left(t_{h}\right), i=1,2 \cdots, n ; h=1,2 \cdots, L\right\}
\end{aligned}
$$

Step 4. Calculate the distance between the evaluation values of alternative $o_{i}$ in the year $t_{h}$ and the best solution, denoted as $d_{i}^{+}\left(t_{h}\right)$, then:

$$
d_{i}^{+}\left(t_{h}\right)=\sqrt{\sum_{j=1}^{m}\left(u_{i j}\left(t_{h}\right)-u_{j}^{+}\right)^{2}}
$$

Similarly, the distance between the evaluation values of alternative $o_{i}$ in the year $t_{h}$ and the worst solution was calculated by:

$$
d_{i}^{-}\left(t_{h}\right)=\sqrt{\sum_{j=1}^{m}\left(u_{i j}\left(t_{h}\right)-u_{j}^{-}\right)^{2}}
$$

Step 5. Calculate the relative performance level of alternative $o_{i}$ in the year $t_{h}$ by comparing the distance between the associated evaluation values and the two ideal solutions:

$$
C_{i}\left(t_{h}\right)=\frac{d_{i}^{-}\left(t_{h}\right)}{d_{i}^{+}\left(t_{h}\right)+d_{i}^{-}\left(t_{h}\right)}
$$

Obviously, $C_{i}\left(t_{h}\right) \in[0,1]$. When the value of $C_{i}\left(t_{h}\right)$ tends to 1 , it indicates better sustainable performance of alternative (city) $o_{i}$, and vice versa.

\section{Results and Discussion}

The actual criteria data were extracted from Liaoning Provincial Statistical Yearbook (2013-2017) [53], Jilin Provincial Statistical Yearbook (2013-2017) [54], Heilongjiang Provincial Statistical Yearbook (2013-2017) [55], and China City Statistical Yearbook (2013-2017) [56]. Based on the dynamic entropy weighting method, TOPSIS steps, and the sustainability criteria, we obtained the sustainable performances of the 34 prefecture-level and above cities in Northeastern China, as shown in Table 2.

To more clearly observe the change of the cities' sustainability in different years, we drew the graphics about the sustainability development trend of the cities in Northeastern China in 2012 to 2016, as shown in Figure 3. 


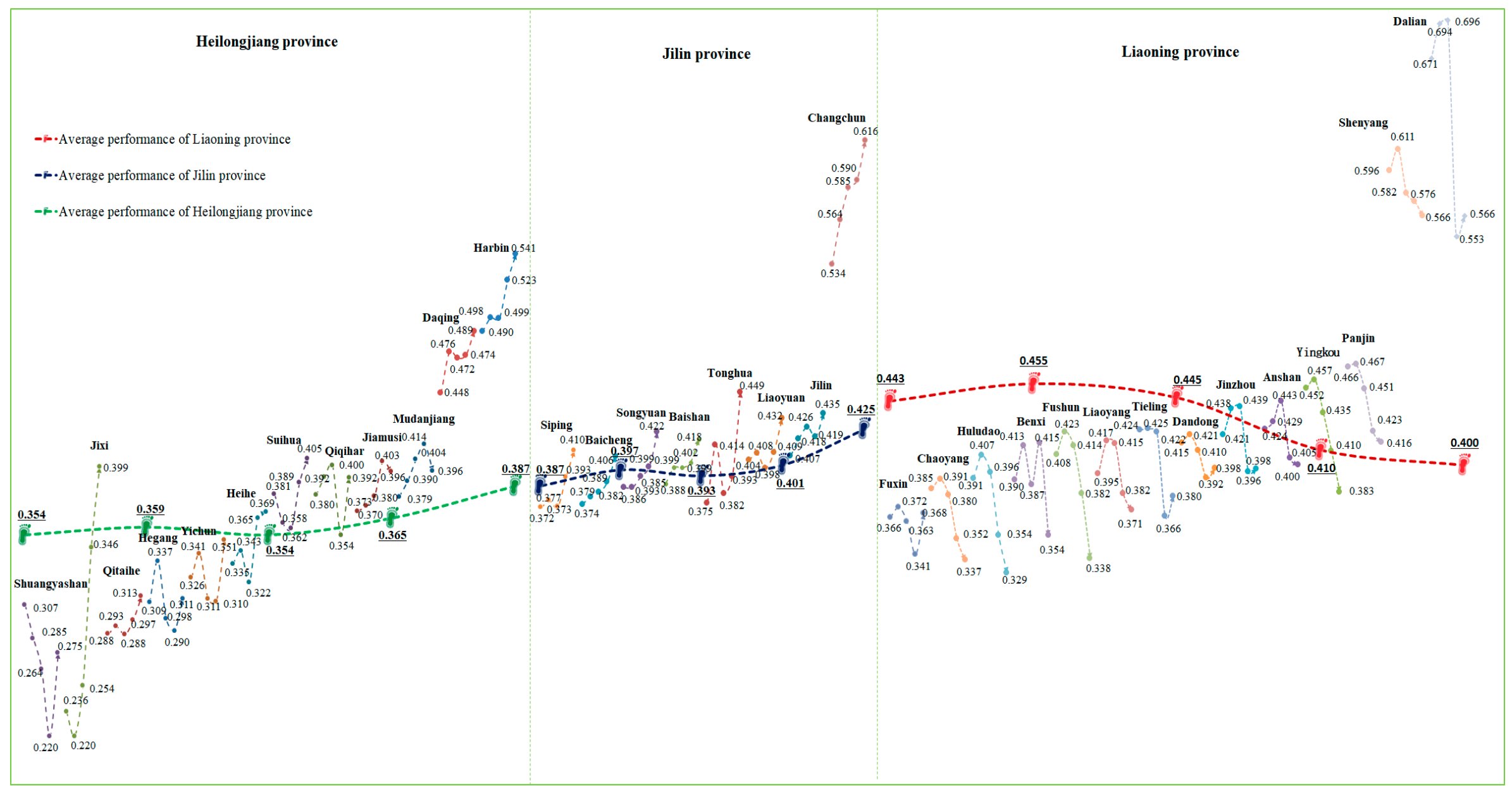

Figure 3. Change of the cities' sustainability in the year 2012 to 2016. Note: Each city had a curve; The points on the curve from left to right represent the sustainable performances of the associated city in the year 2012 to 2016; The average performance of each province in an individual year was calculated by the average performance values of all the cities located in the associated province. 
From Table 2 and Figure 3:

(1) The sustainability of the cities in Northeastern China was comparatively low in the year 2012 to 2016. Only four sub-provincial cities' average performances were over 0.5 (accounting for $11.8 \%$ ), such as Dalian (0.636), Shenyang (0.586), Changchun (0.578), and Harbin (0.510).

(2) The sustainability of Liaoning province showed serious decline in the year 2015 to 2016, whereas Jilin and Heilongjiang provinces had various degrees of increase. In Liaoning province, except for Fuxin, nearly all the cities had negative growth rates. This is the main reason of the decline of Liaoning province's sustainability.

(3) Jixi, located in Heilongjiang province, had the strongest development momentum, with the highest growth rate $(17.23 \%)$. Dalian and Shenyang showed significant declines of their sustainability. For example, the growth rates of the two cities were: Shenyang, $-1.27 \%$ and Dalian, $-3.91 \%$.

(4) All of the cities located in Jilin province had better development momentum. Especially Changchun had a higher sustainability level and showed an increase trend year by year. The sustainability of Harbin also had higher level and better development trend.

The 34 prefecture-level and above cities in Northeastern China were classified into four clusters by the average performances and growth rates, as shown in Figure 4 . The cities located in Cluster I had higher sustainability levels, with average performance values over 0.5 , and better development momentum (positive growth rates). The cities located in Cluster II had lower sustainability levels, but showed better development momentum. The cities in Cluster III had the worst performances and negative growth rates. The cities located in Cluster IV had higher sustainability, but their growth rates were negative, indicating the decline of the cities sustainability.

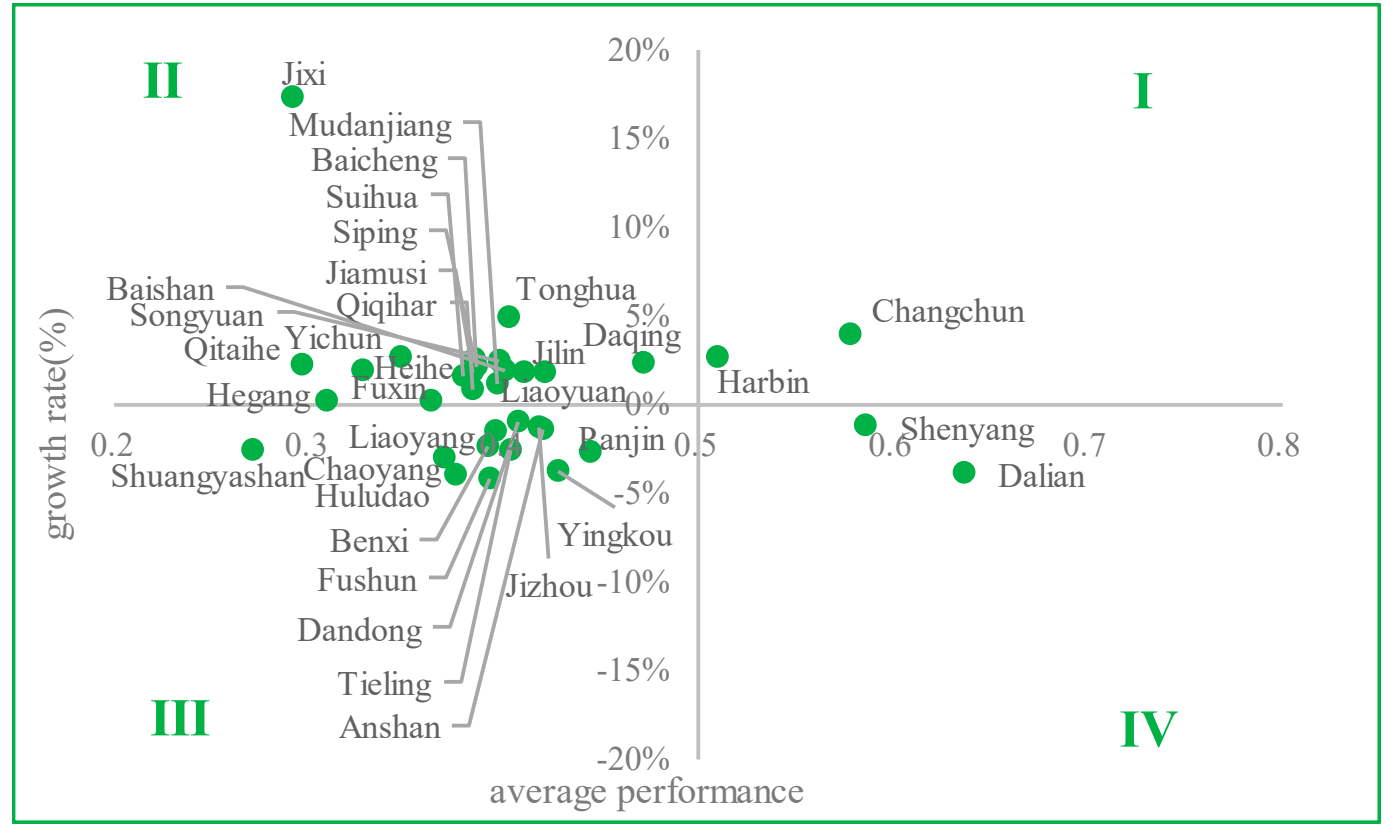

Figure 4. Classification of cities by the average performances and growth rates.

In Figure 4, only two cities (Changchun and Harbin, accounting for 8.3\%) located in Cluster I. In Cluster II, there were 18 cities, accounting for $52.9 \%$. Although these cities had comparatively lower sustainability levels, they showed positive growth rates. However, except for Jixi, the growth rates of all the cities were not very high. Twelve cities located in Cluster III, accounting for 35.3\%, among which eleven cities located in Liaoning province. The cities in Cluster III needed to give more attention to their sustainable development, since they had lower sustainability values and negative growth 
rates. The sustainability advantages of Shenyang and Dalian, located in Cluster IV, were losing for the declines of the growth rates. All of the above indicated that the sustainable development of the cities in Northeastern China was not optimistic. Nearly all the cities, except for Jixi, had dim sustainability as they had lower positive or even negative growth rates.

In addition, the sustainability performances on the three dimensions, economy, society, and environment, were calculated using the dynamic entropy and TOPSIS methods. Then, the sustainability levels (average performance values in 2012 to 2016) of the three dimensions were compared in Figure 5.

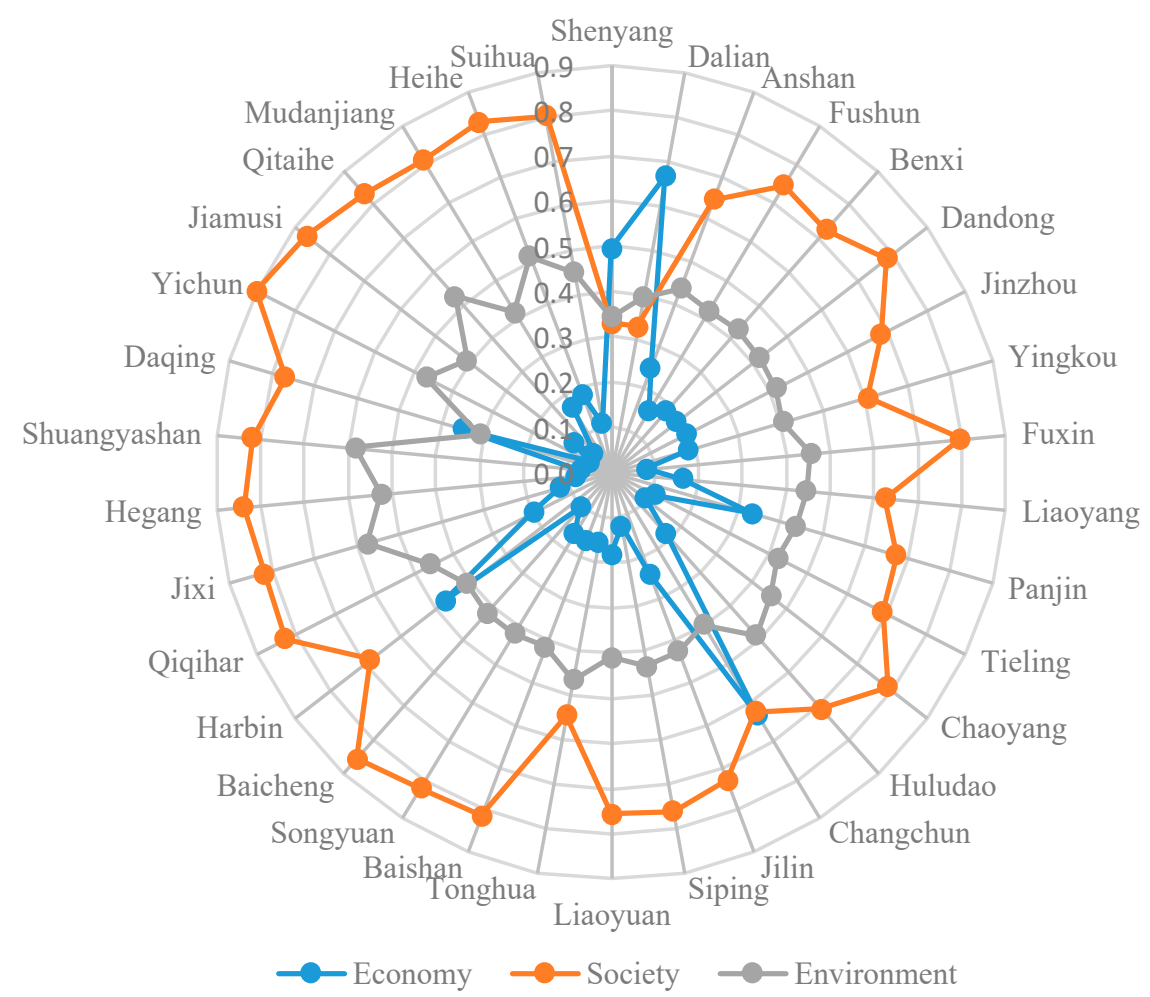

Figure 5. Comparison of the sustainability levels of the three dimensions.

From Figure 5:

(1) Nearly all the cities, except for Shenyang, Dalian, Changchun, Harbin, and Daqing, performed best on the social sustainability. Whereas they had the worst performances on the economic sustainability. The average performance values of economic sustainability were below 0.3. Especially for Yichun, Shuangyashan, Hegang, and Jixi, their average performance values were close to zero. Therefore, improving the economic sustainability is the key to the sustainable development of the cities in Northeastern China.

(2) In terms of the sustainable development on three dimensions, the cities located in Heilongjiang province had the best performances on social sustainability. The cities in Liaoning and Jilin provinces had a comparable level of environmental sustainability. However, their environmental sustainability levels were slightly lower than that in Heilongjiang province.

We calculated the sustainability growth rates of the cities on three dimensions, as shown in Table 3. 
Table 3. Growth rates of the cities' sustainability on three dimensions.

\begin{tabular}{|c|c|c|c|c|c|c|c|}
\hline \multirow{2}{*}{ City } & \multicolumn{3}{|c|}{ Growth Rate } & \multirow{2}{*}{ City } & \multicolumn{3}{|c|}{ Growth Rate } \\
\hline & Economy & Society & Environment & & Economy & Society & Environment \\
\hline Shenyang & $-0.70 \%$ & $3.67 \%$ & $0.03 \%$ & Liaoyuan & $16.44 \%$ & $0.84 \%$ & $-0.65 \%$ \\
\hline Dalian & $-6.06 \%$ & $20.25 \%$ & $1.35 \%$ & Tonghua & $13.53 \%$ & $-1.50 \%$ & $-4.74 \%$ \\
\hline Anshan & $-4.21 \%$ & $0.80 \%$ & $-0.01 \%$ & Baishan & $16.99 \%$ & $-0.18 \%$ & $-0.82 \%$ \\
\hline Fushun & $-0.21 \%$ & $3.47 \%$ & $5.02 \%$ & Songyuan & $10.83 \%$ & $0.01 \%$ & $-1.82 \%$ \\
\hline Benxi & $-6.39 \%$ & $2.92 \%$ & $3.93 \%$ & Baicheng & $19.05 \%$ & $-0.71 \%$ & $-1.58 \%$ \\
\hline Dandong & $-11.43 \%$ & $-0.05 \%$ & $-1.26 \%$ & Harbin & $10.40 \%$ & $5.87 \%$ & $-1.60 \%$ \\
\hline Jinzhou & $-8.45 \%$ & $3.35 \%$ & $-0.97 \%$ & Qiqihar & $6.48 \%$ & $2.09 \%$ & $-1.25 \%$ \\
\hline Yingkou & $-7.05 \%$ & $5.91 \%$ & $3.32 \%$ & Jixi & $11.70 \%$ & $2.53 \%$ & $-9.96 \%$ \\
\hline Fuxin & $-6.10 \%$ & $2.10 \%$ & $-1.15 \%$ & Hegang & $13.38 \%$ & $-0.33 \%$ & $1.68 \%$ \\
\hline Liaoyang & $-5.06 \%$ & $4.85 \%$ & $0.64 \%$ & Shuangyashan & $-10.92 \%$ & $4.65 \%$ & $0.80 \%$ \\
\hline Panjin & $-13.20 \%$ & $0.30 \%$ & $-2.94 \%$ & Daqing & $2.51 \%$ & $1.77 \%$ & $-5.81 \%$ \\
\hline Tieling & $-1.29 \%$ & $7.22 \%$ & $1.79 \%$ & Yichun & $-13.85 \%$ & $-0.14 \%$ & $-3.09 \%$ \\
\hline Chaoyang & $5.78 \%$ & $2.48 \%$ & $3.26 \%$ & Jiamusi & $16.22 \%$ & $1.59 \%$ & $-1.93 \%$ \\
\hline Huludao & $-13.91 \%$ & $3.58 \%$ & $1.45 \%$ & Qitaihe & $1.39 \%$ & $0.53 \%$ & $-2.44 \%$ \\
\hline Changchun & $7.57 \%$ & $-2.09 \%$ & $-2.31 \%$ & Mudanjiang & $31.43 \%$ & $3.47 \%$ & $0.88 \%$ \\
\hline Jilin & $14.06 \%$ & $1.85 \%$ & $-0.52 \%$ & Heihe & $-3.11 \%$ & $0.50 \%$ & $-3.41 \%$ \\
\hline Siping & $16.94 \%$ & $0.55 \%$ & $-2.06 \%$ & Suihua & $13.69 \%$ & $1.67 \%$ & $-1.44 \%$ \\
\hline
\end{tabular}

The cities located in Liaoning province had negative growth rates of economic sustainability, indicating the decline of economy in Liaoning province was serious. This was the main reason of the decline of the province's sustainability. In terms of social sustainability, only one city (accounting for $7.1 \%$ ) had negative growth rate. Five cities (accounting for $35.7 \%$ ) had negative growth rates of environmental sustainability. For the cities located in Jilin province, they all had positive and larger growth rates of economic sustainability, with all the growth rates over $10 \%$. Whereas they had negative growth rates of environmental sustainability. In terms of the cities in Heilongjiang province, nine cities (accounting for 75\%) had negative growth rates of environmental sustainability, and three cities (accounting for 25\%) and two cities (accounting for 16.7\%) had negative growth rates of economic and social sustainability, respectively.

\section{Conclusions and Suggestions}

City sustainable development is very important for the revitalization of Northeastern China. In this paper, we dynamically evaluated the sustainability of the 34 prefecture-level and above cities in Northeastern China. The evaluation results provided us more reference about the development status and trends of the cities' sustainability. The main innovation of this research is that the sustainability performances of the cities across different years (2012-2016) were processed and analyzed as a whole, rather than being evaluated year by year with different weights and ideal solutions. This approach improved the comparability of cities' sustainability in different years.

The evaluation results indicated that the progress of cities sustainable development in Northeastern China was slow from the year 2012 to 2016. For example, Liaoning province showed a decrease trend. The main reason is that the decline of the economic sustainability was serious. Conversely, Jilin and Heilongjiang showed slight increase trends. Only four sub-provincial cities' average performances were over 0.5 (accounting for $11.8 \%$ ). Nearly all the cities, except for Jixi, had dim sustainability for the lower positive or even negative growth rates. In terms of the sustainable development on three dimensions, except for Shenyang, Dalian, Changchun, Harbin, and Daqing, other cities had the worst performance on the economic sustainability. Their average performance values of economic sustainability were below 0.3 .

Based on the findings above, we suggested to firstly improve the economic sustainability of the cities in Northeastern China so as to realize the coordinated development of the three sustainability dimensions. However, the improvement of economic sustainability may need a long time as the institutional and structural contradictions have become more and more apparent in Northeastern 
China. Compared with the cities in eastern coastal regions in China, the equipment and technologies of enterprises in Northeastern China were aged and the leading industries of the cities showed decline. Additionally, the problems of "brain drain" and negative population growth were serious. Some other feasible suggestions were given as follows. The cities located in Liaoning province need to pay more attention to the economic sustainable development, even though their economic basis (or levels) were comparatively better compared with that in Jilin and Heilongjiang provinces. Moreover, partial cities (such as Anshan, Dandong, Jinzhou, Fuxin, and Panjin) in Liaoning province should take action to prevent the decline of environmental sustainability. For the cities in Jilin and Heilongjiang provinces, the decline of their environmental sustainability was serious. This case should arouse the attention of local authorities.

As future work, comparative studies between Northeastern China and other regions in China (such as the eastern coastal regions) or other parts of the world will be considered to discover more detailed reasons about the slow sustainability of Northeastern China. We will discuss the weighting method by considering the interaction among multiple criteria and the development dynamic of an individual criterion across multiple periods. Developing a real-time system to monitor the sustainability of the cities in Northeastern China may also be an important topic of our interest.

Author Contributions: W.L. designed the study and wrote the paper. P.Y. conducted the research and analyzed the data. D.Z. contributed to data collection and process. All authors read and approved the manuscript.

Funding: This research was supported by the National Natural Science Foundation of China (71701040, 71671031, 71803073), the Humanities and Social Sciences Foundation of Chinese Ministry of Education (17YJC630067), and the Fundamental Research Funds for the Central Universities of China (N170604004).

Acknowledgments: Special thanks to the reviewers for their valuable comments.

Conflicts of Interest: The authors declare no conflict of interest.

\section{References}

1. CPC Central Committee and State Council. Certain Opinions Regarding the Comprehensive Revival of Old Industrial Bases Including the Northeast. 2016. Available online: http://www.gov.cn/zhengce/2016-04/26/ content_5068242.htm (accessed on 26 April 2016).

2. Lu, C.; Xue, B.; Lu, C.; Wang, T.; Jiang, L.; Zhang, Z.; Ren, W. Sustainability investigation of resource-based cities in northeastern China. Sustainability 2016, 8, 1058. [CrossRef]

3. Brundtland, G.H. Our Common Future; Oxford University Press: New York, NY, USA, 1987.

4. Ostrom, E. A general framework for analyzing sustainability of social-ecological systems. Science 2009, 325, 419-422. [CrossRef] [PubMed]

5. Halog, A.; Manik, Y. Advancing integrated systems modelling framework for lifecycle sustainability assessment. Sustainability 2011, 3, 469-499. [CrossRef]

6. Yigitcanlar, T.; Dur, F. Developing a sustainability assessment model: The sustainable infrastructure, land-use, environment and transport model. Sustainability 2010, 2, 321-340. [CrossRef]

7. Markard, J.; Raven, R.; Truffer, B. Sustainability transitions: An emerging field of research and its prospects. Res. Policy 2012, 41, 955-967. [CrossRef]

8. Wiek, A.; Withycombe, L.; Redman, C.L. Key competencies in sustainability: A reference framework for academic program development. Sustain. Sci. 2011, 6, 203-218. [CrossRef]

9. Waas, T.; Hugé, J.; Block, T.; Wright, T.; Benitez-Capistros, F.; Aviel Verbruggen, A. Sustainability assessment and indicators: Tools in a decision-making strategy for sustainable development. Sustainability 2014, 6, 5512-5534. [CrossRef]

10. Ness, B.; Urbel-Piirsalu, E.; Anderberg, S.; Olsson, L. Categorising tools for sustainability assessment. Ecol. Econ. 2007, 60, 498-508. [CrossRef]

11. Gibson, R.B. Beyond the pillars: Sustainability assessment as a framework for effective integration of social, economic and ecological considerations in significant decision-making. J. Environ. Assess. Policy Manag. 2006, 8, 259-280. [CrossRef]

12. Gagliardi, F.; Roscia, M.; Lazaroiu, G. Evaluation of sustainability of a city through fuzzy logic. Energy 2007, 32, 795-802. [CrossRef] 
13. Costanza, R. Ecological Economics: The Scienceand Management of Sustainability; Columbia University Press: New York, NY, USA, 1991.

14. Elkington, J. Cannibals with Forks: The Triple Bottom Line of the 21st Century Business; New Society Publishers: Stoney Creek, CT, USA, 1998.

15. Munasinghe, M. Environmental Economics and Sustainable Development; World Bank Publications: Washington, DC, USA, 1993.

16. Ali-Toudert, F.; Ji, L.M. Modelling and measuring urban sustainability in multi-criteria based systems-A challenging issue. Ecol. Indic. 2017, 73, 597-611. [CrossRef]

17. Valentin, A.; Spangenberg, J.H. A guide to community sustainability indicators. Environ. Impact Assess. Rev. 2000, 20, 381-392. [CrossRef]

18. Curwell, S.; Deakin, M.; Symes, M. Sustainability Urban Development: The Environmental Assessment Methods; Taylor \& Francis: London, UK, 2007.

19. Nordo, M.; Saisana, M.; Saltelli, A.; Tarantola, S.; Hoffman, A.; Giovannini, E. Handbookon Constructing Composite Indicators: Methodology and User Guide; OECD Publishing: Paris, France, 2008.

20. Zhou, L.; Tokos, H.; Krajnc, D.; Yang, Y.R. Sustainability performance evaluation in industry by composite sustainability index. Clean Technol. Environ. Policy 2012, 14, 789-803. [CrossRef]

21. Begic, F.; Afgan, N. Sustainability assessment tool for the decision making in selection of energy system: Bosnian case. Energy 2007, 32, 1979-1985. [CrossRef]

22. Hu, A.H.; Chen, L.T.; Hsu, C.W.; Ao, J.G. An evaluation framework for scoring corporate sustainability reports in Taiwan. Environ. Eng. Sci. 2011, 28, 843-858. [CrossRef]

23. Lee, G.K.L.; Chan, E.H.W. The analytic hierarchy process (AHP) approach for assessment of urban renewal proposals. Soc. Indic. Res. 2008, 89, 155-168. [CrossRef]

24. Büyükozkan, G.; Karabulut, Y. Energy project performance evaluation with sustainability perspective. Energy 2017, 119, 549-560. [CrossRef]

25. Zhang, L.; Xu, Y.; Yeh, C.H.; Liu, Y.; Zhou, D.Q. City sustainability evaluation using MCDM with objective weights of interdependent criteria. J. Clean. Prod. 2016, 131, 491-499. [CrossRef]

26. Afgan, N.H.; arvalho, M.G. Sustainability assessment of hydrogen energy systems. Int. J. Hydrog. Energy 2004, 29, 1327-1342. [CrossRef]

27. VandeKerk, G.; Manuel, A.R. A comprehensive index for a sustainable society: The SSI-the sustainable society index. Ecol. Econ. 2008, 66, 228-242. [CrossRef]

28. Shannon, C.E. A mathematical theory of communication. Bell Syst. Tech. J. 1948, 27, 379-423. [CrossRef]

29. Zinatizadeh, S.; Azmi, A.; Monavari, S.M.; Sobhanardakani, S. Evaluation and prediction of sustainability of urban areas: A case study for Kermanshah city, Iran. Cities 2017, 66, 1-9. [CrossRef]

30. Munier, N. Methodology to select a set of urban sustainability indicators to measure the state of the city, and performance assessment. Ecol. Indic. 2011, 11, 1020-1026. [CrossRef]

31. Lin, Z.; Xia, B. Sustainability analysis of the urban ecosystem in Guangzhou city based on information entropy between 2004 and 2010. J. Geogr. Sci. 2013, 23, 417-435. [CrossRef]

32. Hwang, C.L.; Yoon, K. Multiple Attribute Decision Making: Methods and Application a State-of-Art Survey; Springer: Berlin/Heidelberg, Germany, 1981.

33. Kaya, T.; Kahraman, C. Multicriteria decision making in energy planning using amodified fuzzy TOPSIS methodology. Expert Syst. Appl. 2011, 38, 6577-6585. [CrossRef]

34. Chen, C.T. Extensions of the TOPSIS for group decision-making under fuzzy environment. Fuzzy Sets Syst. 2000, 114, 1-9. [CrossRef]

35. Li, D.F. TOPSIS-based nonlinear-programming methodology for multiattribute decision making with interval-valued intuitionistic fuzzy sets. IEEE Trans. Fuzzy Syst. 2010, 18, 299-311. [CrossRef]

36. Shih, H.S.; Shyur, H.J.; Lee, E.S. An extension of TOPSIS for group decision making. Math. Comput. Model. 2007, 45, 801-813. [CrossRef]

37. Alptekin, N. Ranking of EU countries and Turkey in terms of sustainable development indicators: An integrated approach using entropy and TOPSIS methods. In Proceedings of the 9th International Days of Statistics and Economics, Prague, Czech, 10-12 September 2015; pp. 22-32.

38. Sen, N.; Ghosh, A.; Saha, A.; Karmaker, B.R. Sustainability status of Indian states: Application and assessment of MCDM frameworks. In Proceedings of the 2014 IEEE Symposium on Computational Intelligence in Multi-Criteria Decision-Making (MCDM), Orlando, FL, USA, 9-12 December 2014; pp. 78-85. 
39. Balcerzak, A.P.; Pietrzak, M.B. Application of TOPSIS method for analysis of sustainable development in European Union countries. In Proceedings of the 10th International Days of Statistics and Economics. Conference Proceedings, Prague, Czech, 8-10 September 2016; Volume 1, pp. 82-92.

40. Dias, J.M.A.; Salgado, E.G.; Barbosa, S.; Alvarenga, A.D.; Lira, J.M.S. Assessment of the sustainability of countries at worldwide. J. Manag. Sustain. 2017, 7, 51-64. [CrossRef]

41. Ding, L.; Shao, Z.; Zhang, H.; Xu, C.; Wu, D. A comprehensive evaluation of urban sustainable development in China based on the TOPSIS-Entropy method. Sustainability 2016, 8, 746. [CrossRef]

42. Liang, X.; Zhang, W.; Chen, L.; Deng, F. Sustainable urban development capacity measure-A case study in Jiangsu province, China. Sustainability 2016, 8, 270. [CrossRef]

43. Guo, H.; Liu, X.; Li, Y.; Wang, E.; Chen, X. Comparison analysis and evaluation of urban competitiveness in Chinese urban clusters. Sustainability 2015, 7, 4425-4447. [CrossRef]

44. Tan, F.; Lu, Z. Assessing regional sustainable development through an integration of nonlinear principal component analysis and Gram Schmidt orthogonalization. Ecol. Indic. 2016, 63, 71-81. [CrossRef]

45. Xu, C.; Wang, S.; Zhou, Y.; Wang, L.; Liu, W. A comprehensive quantitative evaluation of new sustainable urbanization level in 20 Chinese urban agglomerations. Sustainability 2016, 8, 91. [CrossRef]

46. Shen, L.; Shuai, C.; Jiao, L.; Tan, Y.; Song, X. Dynamic sustainability performance during urbanization process between BRICS countries. Habitat Int. 2017, 60, 19-33. [CrossRef]

47. Lin, W.; Li, Y.; Li, X.; Xu, D. The dynamic analysis and evaluation on tourist ecological footprint of city: Take Shanghai as an instance. Sustain. Cities Soc. 2018, 37, 541-549. [CrossRef]

48. Li, K.; Yi, P.T.; Wang, S.Q.; Xiang, T. Evaluation Report on the Overall Revitalization of Northeast Old Industrial Base 2016; Economy \& Management Publishing House: Beijing, China, 2017.

49. Research group on sustainable development strategy, Chinese academy of sciences (CAS). China Sustainable Development Report 2015: Reshaping the Governance for Sustainable Development; Science Press: Beijing, China, 2015.

50. China City Development Academy (CCDA). Comprehensive Evaluation Report of Chinese Urban Scientific Development; Press of Social Science: Beijing, China, 2010.

51. Gu, L.J. Low Carbon City: The New Idea of Chinese Urbanization. Future Dev. 2010, 3, $2-5$.

52. Yan, J.H.; Feng, C.H.; Li, L. Sustainability assessment of machining process based on extension theory and entropy weight approach. Int. J. Adv. Manuf. Technol. 2014, 71, 1419-1431. [CrossRef]

53. Liaoning Bureau of Statistics. Liaoning Provincial Statistical Yearbook (2013-2017); China Statistics Press: Beijing, China, 2017.

54. Jilin Bureau of Statistics. Jilin Provincial Statistical Yearbook (2013-2017); China Statistics Press: Beijing, China, 2017.

55. Heilongjiang Bureau of Statistics. Heilongjiang Provincial Statistical Yearbook (2013-2017); China Statistics Press: Beijing, China, 2017.

56. National Bureau of Statistics. China City Statistical Yearbook (2013-2017); China Statistics Press: Beijing, China, 2017.

(C) 2018 by the authors. Licensee MDPI, Basel, Switzerland. This article is an open access article distributed under the terms and conditions of the Creative Commons Attribution (CC BY) license (http://creativecommons.org/licenses/by/4.0/). 